\title{
Twenty years of Information Systems Frontiers
}

\author{
Ghassan Beydoun ${ }^{1}$, Babak Abedin ${ }^{1}$, José M. Merigó ${ }^{1,2}$, Melanie Vera ${ }^{2}$ \\ ${ }^{1}$ School of Information, Systems and Modelling, Faculty of Engineering and Information Technology, \\ University of Technology Sydney, 81 Broadway, Ultimo 2007, NSW, Australia \\ ${ }^{2}$ Department of Management Control and Information Systems, School of Economics and Business, \\ University of Chile, Av. Diagonal Paraguay 257, 8330015 Santiago, Chile \\ Emails: Ghassan.Beydoun@uts.edu.au;Babak.Abedin@uts.edu.au; Jose.Merigo@uts.edu.au; \\ mevera@fen.uchile.cl
}

\begin{abstract}
Information Systems Frontiers is a leading international journal that publishes research at the interface between information systems and information technology. The journal was launched in 1999. In 2019, the journal celebrates the 20th anniversary. Motivated by this event, this paper aims to review this first twenty years of publication record to uncover trends most influential on ISF. The analysis considers various metics including citation structure of the journal, most-cited papers, the most influential authors, institutions and countries, and citing articles. Importantly, the paper presents a thematic analysis of the publications that appeared in ISF in the past 20 years. The thematic analysis is evidenced by two sources of data: First, a bibliometric analysis highlighting core topics within the past 20 years is presented. Second, a semantic analysis of keywords introduced by the authors themselves is applied.
\end{abstract}

Keywords: Bibliometrics; Web of Science; co-citation; VOS viewer. 


\section{Introduction}

Founded in 1999, Information Systems Frontiers (ISF) is a respected and highly cited journal. With a 2017 impact factor of 3.323, the journal has emerged as a quality outlet for publishing IS research by scholars from all over the world. The journal is highly ranked in various ranking systems. For example, Scimago Journal \& Country recently upgraded ISF rank from Quarter $2(\mathrm{Q} 2)$ to Quarter $1(\mathrm{Q} 1)$ in Information Systems, both the Australian Deans of Business Council (ABDC) and the Australian Council of Professors and Heads of IS (ACPHIS) rank ISF in the highest 'A' category. Indeed, ISF has enjoyed a consistent increase in the number of published articles from 1999 until today.

Motivated by the 20th anniversary of ISF, this paper reviews ISF papers between 1999 and 2018. This uncover the trends that have had more influence. The analysis considers a wide range of issues including the publication and citation structure of the journal, mostcited papers, most influential authors, institutions and countries, and citing articles. Importantly, the paper presents a thematic analysis of the publications that appeared in ISF in the past 20 years. The thematic analysis is evidenced by two sources of data: First source is a bibliometric analysis highlighting core topics within the past 20 years. Second source is a semantic analysis of keywords introduced by the authors themselves. The thematic analysis will show that ISF is steadily concerned with core IS topics such as Enterprise Architectures and IS use. At the same time, ISF is maintaining currency with emerging topics of increasing importance such as IS for social good, analytics and Internet of Things (IoT).

The aim of this paper is two fold: First, the paper aims to provide an overview of the bulk of ISF papers. Second, it aims to uncover trends in an evidence-based fashion. We use a bibliometric analysis to fulfil the first aim and at the same time provide early evidence towards uncovering key trends. For the IS community, uncovering trends in the emphasis across IS would be most instructive. Towards this, the paper first provides a bibliometric analysis that is essentially a data extraction process. This is followed by a correlation analysis supported by a visual analysis. Finally, an IS-based thematic analysis using keywords of each publication is used to achieve the overall aim of the paper.

Hence, the paper is organised as follows: Section 2 presents the bibliometric methods and descriptive results. Section 3 presents the correlation analysis and a graphical mapping of the bibliographic material of ISF by using the visualization of similarities (VOS) viewer 
software. Section 5 analyzes the thematic structure of the journal, and Section 6 ends the paper summarizing the main conclusions and findings.

\section{Bibliometric Analysis}

\subsection{Bibliometric Methods}

In order to develop the bibliometric analysis, we first define the bibliometric indicators that we used in the analysis. Various indicators have been used in the literature (Alonso et al. 2009; Ding et al. 2014). This study aims to provide a simple and complete overview of the publications of the journal. Various interests and potential perspectives of readers are accomodated. There is no single indicator that can totally represent the results of a set of documents. Each expert may evaluate the results in different ways according to his or her interpretation. Some experts may give more importance to the number of publications as a measure of productivity while some other ones may give more relevance to the number of citations as a measure of popularity and influence. Many other indicators could also be considered. This work aims to provide different perspectives by presenting each analysis considering several representative indicators. It focuses on the number of publications and citations, the number of cites per paper, citation thresholds and the h-index. In some specific cases, the work also considers some other indicators including the world university ranking in the Shanghai and QS rankings and the results per capita at the country level.

The search process uses the Web of Science Core Collection database and analyses all ISF publications between 1999 and 2018. ISF has been available in Web of Science since 2001. Hence, the search identifies all results between 2001 and 2018. Nevertheless, for documents published between 1999 and 2000, the work develops a manual search by using

the Cited Reference Search tool of Web of Science Core Collection. Here, the search identifies all the documents that have received at least one citation in Web of Science Core Collection. In addition, for those documents that have zero citations in Web of Science, the study identifies them through the webpage of the journal (https://link.springer.com/journal/10796). 


\subsection{Bibliometric Results}

ISF has published 855 documents between 1999 and 2018 if only considering articles, reviews and letters. Note that ISF has also published approximately eighty documents classified as editorials and corrections. Since these documents are not strictly a scientific contribution, they are not included in the bibliometric analysis. The 855 documents considered in the analysis have received 9888 citations up to august 2018 . Thus, the cites per paper ratio of ISF is 11.56. The h-index is 43. That is, of the 855 documents, 43 have received 43 citations or more and the same time there are not 44 documents that have received 44 citation or more. Figure 1 presents the annual number of papers published each year in ISF. This increased from around twenty articles per year during the first years to eighty documents in the last years.

Table 1 presents several annual citation thresholds that the papers published in ISF has reached over time. Currently, $1 \%$ of the articles published in ISF have obtained more than one hundred citations and $4 \%$ more than fifty citations. Around $60 \%$ of the papers have received at least five citations and more than $95 \%$ of the documents at least receive one citation. ISF publications are clearly having a strong academic impact. The most cited papers published in ISF according to Web of Science Core Collection are shown in Table 2.

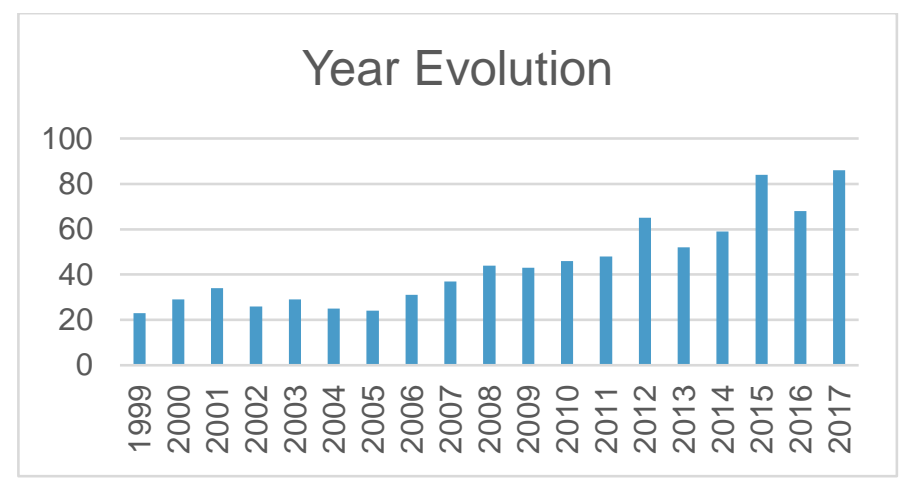

Figure 1. Annual number of papers published in ISF 
Table 1. Annual citation structure of ISF

\begin{tabular}{ccccccccc}
\hline Year & TP & TC & $\geq 100$ & $\geq 50$ & $\geq 25$ & $\geq 10$ & $\geq 5$ & $\geq 1$ \\
\hline 1999 & 23 & 163 & 0 & 0 & 1 & 6 & 11 & 16 \\
2000 & 29 & 859 & 2 & 4 & 7 & 16 & 25 & 29 \\
2001 & 34 & 778 & 0 & 5 & 12 & 20 & 31 & 34 \\
2002 & 26 & 213 & 0 & 0 & 2 & 7 & 14 & 26 \\
2003 & 29 & 592 & 2 & 3 & 6 & 12 & 20 & 28 \\
2004 & 25 & 329 & 1 & 2 & 3 & 6 & 12 & 22 \\
2005 & 24 & 356 & 1 & 1 & 2 & 10 & 19 & 24 \\
2006 & 31 & 527 & 0 & 1 & 6 & 18 & 25 & 31 \\
2007 & 37 & 489 & 0 & 1 & 4 & 18 & 31 & 37 \\
2008 & 44 & 1117 & 1 & 6 & 13 & 33 & 39 & 44 \\
2009 & 43 & 534 & 0 & 1 & 7 & 17 & 30 & 43 \\
2010 & 46 & 740 & 0 & 4 & 8 & 24 & 35 & 46 \\
2011 & 48 & 565 & 0 & 2 & 5 & 17 & 32 & 48 \\
2012 & 65 & 577 & 0 & 0 & 6 & 16 & 37 & 65 \\
2013 & 52 & 355 & 0 & 0 & 1 & 17 & 31 & 48 \\
2014 & 59 & 478 & 0 & 1 & 3 & 14 & 31 & 56 \\
2015 & 84 & 908 & 2 & 2 & 6 & 19 & 41 & 76 \\
2016 & 68 & 190 & 0 & 0 & 0 & 3 & 12 & 55 \\
2017 & 86 & 128 & 0 & 0 & 0 & 2 & 8 & 50 \\
\hline Total & 855 & 9888 & 9 & 33 & 92 & 275 & 484 & 778 \\
\hline$\%$ & $100 \%$ & - & $1.12 \%$ & $4.11 \%$ & $11.46 \%$ & $34.25 \%$ & $60.27 \%$ & $96.89 \%$ \\
\hline
\end{tabular}

Abbreviations: TP and TC $=$ Total papers and citations; $\geq 100, \geq 50, \geq 25, \geq 10, \geq 5, \geq 1=$ Number of papers with equal or more than $100,50,25,10,5$ and 1 citations.

As Table 2 shows (full list of references is shown in Appendix I), the paper by Klaus et al. (2000) on enterprise resource planning (ERP) has attracted the highest citation. This paper was one of the earliest studies in the IS field that tried to synthesize the literature to explore what and their benefits ERPs are about. Ross and Vitale (2000) paper on ERP ranks forth in the list and highlights that information systems integration is still a relevant topic to IS scholars in 2019.

Table 2. The 20 most cited documents in ISF

\begin{tabular}{|c|c|c|c|c|c|}
\hline $\mathrm{R}$ & $\mathrm{TC}$ & Title & Author/s & Year & $\begin{array}{l}\text { Citations } \\
\text { per year }\end{array}$ \\
\hline 1 & 211 & What is ERP? & Klaus, H; Rosemann, M; Gable, GG & 2000 & 12.41 \\
\hline 2 & 190 & The Internet of Things - A survey of topics and trends & Whitmore, A; Agarwal, A; Xu, LD & 2015 & 95.00 \\
\hline 3 & 178 & The Internet of things: a survey & $\mathrm{Li}, \mathrm{S} ; \mathrm{Xu}, \mathrm{LD} ; \mathrm{Zhao}, \mathrm{S}$ & 2015 & 89.00 \\
\hline 4 & 160 & The ERP revolution: surviving vs. thriving & Ross, JW; Vitale, MR & 2000 & 9.41 \\
\hline 5 & 135 & E-government adoption: A cultural comparison & Carter, L; Weerakkody, V & 2008 & 15.00 \\
\hline 6 & 127 & $\begin{array}{l}\text { Powering e-Learning in the new millennium: An overview of e-Learning and } \\
\text { enabling technology }\end{array}$ & Zhang, DS; Nunamaker, JE & 2003 & 9.07 \\
\hline 7 & 126 & Propagation models for trust and distrust in social networks & Ziegler, CN; Lausen, G & 2005 & 10.50 \\
\hline 8 & 123 & $\begin{array}{l}\text { An integrated framework for service quality, customer value, satisfaction: } \\
\text { Evidence from China`s telecommunication industry }\end{array}$ & Wang, YG; Lo, HP; Yang, YH & 2004 & 9.46 \\
\hline 9 & 114 & Combinatorial information market design & Hanson, $\mathrm{R}$ & 2003 & 8.14 \\
\hline 10 & 99 & Workflow automation: Overview and research issues & Stohr, EA; Zhao, JL & 2001 & 6.19 \\
\hline 11 & 91 & Understanding the behavior of mobile data services consumers & Hong, SJ; Thong, JYL; Moon, JY; et al. & 2008 & 10.11 \\
\hline 12 & 85 & Evaluation on crowdsourcing research: Current status and future direction & Zhao, Y; Zhu, Q & 2014 & 28.33 \\
\hline 13 & 85 & $\begin{array}{l}\text { Challenges and obstacles in sharing and coordinating information during multi- } \\
\text { agency disaster response: Propositions from field exercises }\end{array}$ & Bharosa, N; Lee, JK; Janssen, M & 2010 & 12.14 \\
\hline 14 & 85 & $\begin{array}{l}\text { Implementing enterprise resource planning systems: the role of learning from } \\
\text { failure }\end{array}$ & Scott, JE; Vessey, I & 2000 & 5.00 \\
\hline 15 & 78 & Prediction markets as decision support systems & Berg, JE; Rietz, TA & 2003 & 5.57 \\
\hline 16 & 77 & $\begin{array}{l}\text { Investigating mobile wireless technology adoption: An extension of the } \\
\text { technology acceptance model }\end{array}$ & Kim, S; Garrison G & 2009 & 9.63 \\
\hline
\end{tabular}




\begin{tabular}{|c|c|c|c|c|c|}
\hline 17 & 76 & $\begin{array}{l}\text { The impaction of cultural differences in offshore outsourcing - Case study results } \\
\text { from German-Indian Application development projects }\end{array}$ & Winkler, J; Dibbern, J; Heinzi, A & 2008 & 8.44 \\
\hline 18 & 71 & $\begin{array}{l}\text { Service quality and perceived value`s impact on satisfaction, intention and usage } \\
\text { of short message service (SMS). }\end{array}$ & Lai, TL & 2004 & 5.46 \\
\hline 19 & 66 & $\begin{array}{l}\text { Supply Chain Operations Reference Model version 5.0: A new tool to improve } \\
\text { supply chain efficiency and achieve best practice }\end{array}$ & Stephens, S & 2001 & 4.13 \\
\hline 20 & 65 & Enterprise architecture analysis with extended influence diagrams & $\begin{array}{l}\text { Johnson, P; Lagerstrom, R; Narman, P; } \\
\text { et al. }\end{array}$ & 2007 & 6.50 \\
\hline
\end{tabular}

Both Klaus et al. (2000) and Ross and Vitale (2000) papers made a number of foundamental suggestions for guiding research as well as teaching, which led to a lot of attention within IS and other diciplines. Furthemore, while just recently published in 2015, the papers by Whitmore and colleagues and $\mathrm{Li}, \mathrm{Xu}$, and Zhao on the Internet of Things rank second and third in the above table, which highlights the overwhelming interest in this topic.

Table 3 presents the 20 most cited documents in ISF. Fornell and Lacker (1981) paper on evaluating structural equation models with unobservable variables and measurement error is the most highly cited publication in this table. This paper is actually very highly cited in many other diciplines, thanks to its foundamental and practical guides on the use of structural equation models for business, technology, and social science research. Next in the list is Davis (1989)'s popular Technology Acceptance Model (TAM), followed by Hevner's (2004) paper on design science in Information Systems research, which undoubtedly have inspired and impacted many studies in IS and other diciplines over the past decades.

Table 3. Top 20 most cited documents in ISF publications

\begin{tabular}{|c|c|c|c|c|c|c|c|c|}
\hline Rank & Year & First author & Reference & $\mathrm{Vol}$ & Page & Type & $T C$ & Co-citations \\
\hline 1 & 1981 & Fornell C & J Marketing Res & $\mathrm{V} 18$ & P39 & $\mathrm{A}$ & 42 & 41 \\
\hline 2 & 1989 & Davis FD & MIS Quart & V13 & P319 & A & 37 & 34 \\
\hline 3 & 2004 & Hevner AR & MIS Quart & V28 & P75 & A & 29 & 23 \\
\hline 4 & 2003 & Podsakoff PM & J Appl Psychol & V88 & P879 & A & 25 & 25 \\
\hline 5 & 1991 & Ajzen I & Organ Behav Hum Dec & V50 & P179 & A & 24 & 22 \\
\hline 6 & 1989 & Davis FD & Manage Sci & V35 & P982 & A & 24 & 23 \\
\hline 7 & 1995 & Rogers E & Diffusion Innovation & & & B & 23 & 20 \\
\hline 8 & 2003 & Venkatesh V & MIS Quart & V27 & $\mathrm{P} 425$ & A & 23 & 23 \\
\hline 9 & 1992 & Delone WH & Inform Syst Res & V3 & P60 & A & 22 & 21 \\
\hline 10 & 2003 & Delone WH & J Manage Inform Syst & V19 & P9 & A & 19 & 18 \\
\hline 11 & 1975 & Fishbein M & Belief Attitude Inte & & & $\mathrm{B}$ & 18 & 18 \\
\hline 12 & 1989 & Eisenhardt KH & Acad Manage Rev & V14 & P532 & A & 17 & 11 \\
\hline 13 & 2000 & Gefen D & Communications Ass I & V4 & $\mathrm{P} 1$ & A & 17 & 17 \\
\hline 14 & 1991 & Moore GC & Inform Syst Res & $\mathrm{V} 2$ & P192 & A & 16 & 16 \\
\hline 15 & 1978 & Nunnally JC & Psychometric Theory & & & $\mathrm{B}$ & 16 & 15 \\
\hline 16 & 1994 & Miles M & Qualitative Data Ana & & & $\mathrm{B}$ & 15 & 11 \\
\hline 17 & 2003 & Rogers EM & Diffusion Innovation & & & $\mathrm{B}$ & 15 & 14 \\
\hline 18 & 1995 & Taylor S & Inform Syst Res & V6 & P144 & A & 15 & 15 \\
\hline 19 & 2001 & Alavi M & MIS Quart & $\mathrm{V} 25$ & P107 & A & 14 & 12 \\
\hline 20 & 1988 & Anderson JC & Psychol Bull & V103 & P411 & A & 14 & 14 \\
\hline
\end{tabular}

An analysis of ISF publications at the country level is shown in Table 4. This presents the countries with the highest number of publications in ISF and showing the annual evolution 
of the publications. The USA is by far the country with the highest number of publications in ISF. However, it is worth noting the growth of China that currently is in the second position. UK, Australia and Canada are also notable given their smaller size. Some other Asian countries feature on this list, e.g. South Korea and Taiwan. Some other European countries also regularly feature in the journal, e.g. Germany, Netherlands and Spain. Next, let us analyze the citing articles to guage the readership of ISF. That is, those documents that give at least one citation to ISF. Here, the work considers the universities, countries and journals that have cited ISF in the highest number of articles. Table 5 presents the Top 30. ISF broad impact is evident. USA is currently the leading country in readership followed by China. There is also broad readership from developing countries including India, Iran, Malaysia, Turkey, Pakistan and South Africa. From the journal point of view (right side of Table 5), the self-citations of ISF are the most common ones which is a very common result for most of the journals. Other journals citing frequently ISF are Computers in Human Behavior, Decision Support Systems, Expert Systems with Applications and Enterprise Information Systems. Whilst most of the top citing journals are IS or IT journals, it is also worth noting that some other journals with a broader scope, specially in computer science, also appear among the Top 30.

Table 4. Annual number of papers classified by countries

\begin{tabular}{|c|c|c|c|c|c|c|c|c|c|c|c|c|c|c|c|c|c|c|c|c|c|}
\hline $\mathrm{R}$ & Country & 99 & 00 & 01 & 02 & 03 & 04 & 05 & 06 & 07 & 08 & 09 & 10 & 11 & 12 & 13 & 14 & 15 & 16 & 17 & Total \\
\hline 1 & USA & 18 & 20 & 20 & 13 & 25 & 14 & 8 & 13 & 17 & 25 & 9 & 23 & 20 & 18 & 6 & 16 & 33 & 13 & 26 & 337 \\
\hline 2 & China & & 2 & & & & 2 & & 1 & 5 & 9 & 5 & 9 & 11 & 7 & 9 & 17 & 20 & 4 & 17 & 118 \\
\hline 3 & UK & & 2 & 4 & 5 & 1 & & 3 & 2 & 4 & 3 & 3 & 5 & 2 & 4 & 2 & 7 & 17 & 4 & 9 & 77 \\
\hline 4 & Australia & & 4 & 4 & & 1 & 1 & 1 & & 4 & 3 & 6 & 3 & 5 & 6 & 7 & & 8 & 11 & 4 & 68 \\
\hline 5 & Canada & & & & 3 & 5 & 1 & & 6 & 3 & 5 & 3 & 2 & 5 & 6 & 4 & 5 & 1 & 6 & 4 & 59 \\
\hline 6 & $\begin{array}{l}\text { South } \\
\text { Korea }\end{array}$ & & & 1 & & & 3 & 1 & 1 & 3 & 3 & 8 & 2 & 3 & 12 & 3 & 4 & 5 & 1 & 8 & 58 \\
\hline 7 & Taiwan & & & & & & 1 & 1 & 2 & & & 6 & & 4 & 7 & 4 & 7 & 7 & 2 & 7 & 48 \\
\hline 8 & Germany & & 4 & 1 & 1 & & & 4 & 1 & 2 & 3 & 1 & 3 & 6 & 4 & 4 & 1 & 1 & 5 & 6 & 47 \\
\hline 9 & Netherlands & & & 2 & 2 & & & 1 & 3 & 3 & 1 & 3 & 6 & 1 & 2 & 1 & & 3 & 2 & 5 & 35 \\
\hline 10 & Spain & & & 1 & & & & & & 1 & & 1 & 1 & & 3 & 5 & 10 & 4 & 5 & 1 & 32 \\
\hline 11 & Italy & & & 1 & & 1 & 2 & 1 & & 4 & & 1 & 2 & & 1 & 3 & & & 1 & & 17 \\
\hline 12 & India & 1 & & & & & 1 & 1 & & & & 1 & & & & 1 & & 4 & 2 & 5 & 16 \\
\hline 13 & Portugal & & & & & & & & & & & & & & 1 & & 1 & 1 & 6 & 3 & 12 \\
\hline 14 & France & & & & & & & & & & & & & & 1 & 1 & 2 & 3 & 4 & & 11 \\
\hline 15 & Greece & & & & & & 1 & 1 & & 2 & & 1 & 2 & & 2 & & & & & 1 & 10 \\
\hline 16 & Japan & & & & & & 1 & & 3 & & & 1 & & 1 & & 2 & 1 & & & 1 & 10 \\
\hline 17 & Sweden & & & 1 & & & & 1 & 2 & 1 & & & & & & & & 2 & 1 & 2 & 10 \\
\hline 18 & $\begin{array}{l}\text { U Arab } \\
\text { Emirates }\end{array}$ & & & & & & & & & & & 1 & 1 & 1 & & & & 1 & & 6 & 10 \\
\hline 19 & Denmark & & & & 1 & & & & & & 2 & & 1 & & & & 1 & 2 & 1 & 1 & 9 \\
\hline 20 & $\begin{array}{l}\text { New } \\
\text { Zealand }\end{array}$ & & & 1 & & & & & 1 & & & & & & 1 & 1 & & 2 & 2 & 1 & 9 \\
\hline
\end{tabular}


Table 5. Citing articles of ISF: countries and journals

\begin{tabular}{|c|c|c|c|}
\hline Country & TP & Journal & $\mathrm{TP}$ \\
\hline USA & 1114 & Information Systems Frontiers & 278 \\
\hline China & 808 & Computers in Human Behavior & 71 \\
\hline UK & 418 & Decision Support Systems & 62 \\
\hline Australia & 291 & Expert Systems with Applications & 58 \\
\hline South Korea & 267 & Enterprise Information Systems & 54 \\
\hline Spain & 256 & Int J Information Management & 41 \\
\hline Taiwan & 251 & IEEE Access & 36 \\
\hline Germany & 233 & Int J Production Economics & 36 \\
\hline Canada & 201 & J Network and Computer Applications & 36 \\
\hline India & 154 & Int J Production Research & 32 \\
\hline Netherlands & 136 & MIS Quarterly & 32 \\
\hline Italy & 124 & Information Management & 31 \\
\hline France & 115 & European J Information Systems & 30 \\
\hline Iran & 111 & Government Information Quarterly & 30 \\
\hline Malaysia & 106 & Internet Research & 30 \\
\hline Finland & 81 & J Systems and Software & 29 \\
\hline Saudi Arabia & 71 & Telematics and Informatics & 29 \\
\hline Brazil & 68 & Information Technology Management & 28 \\
\hline Greece & 67 & Industrial Management Data Systems & 27 \\
\hline Sweden & 67 & Sensors & 27 \\
\hline Turkey & 67 & Future Generation Computer Syst & 26 \\
\hline Austria & 64 & Information and Software Technology & 26 \\
\hline Portugal & 62 & Behaviour Information Technology & 23 \\
\hline Japan & 57 & Information Science & 23 \\
\hline Norway & 52 & J Computer Information Systems & 23 \\
\hline New Zealand & 50 & Tech Forecasting Social Change & 23 \\
\hline Pakistan & 49 & Int J Mobile Communications & 22 \\
\hline Denmark & 46 & Business Information Syst Engin & 21 \\
\hline South Africa & 42 & Electronic Commerce Res Applic & 21 \\
\hline U Arab Emirates & 42 & J Management Information Syst & 21 \\
\hline
\end{tabular}

\section{Correlation Analysis and Graphical Mapping}

VOS (Visualisation of Similarities) viewer (Van Eck and Waltman, 2010) is a computer software that collects the bibliographic material and builds graphical maps by using bibliographic coupling, co-citation and co-occurrence of keywords (Blanco-Mesa et al. 2017; Cancino et al. 2017). We use VOS to produce a graphical mapping of bibliographic couplings in ISF. Recall that bibliographic coupling occurs when two documents cite the same third work (Kessler, 1963). Co-citation appears when two studies receive a citation from the same third work (Small, 1973). Co-occurrence of author keywords measures the most common keywords and those that appear more frequently in the same documents (Laengle et al. 2018).

First, let us consider co-citation of journals. That is, when two journals receive a citation from the same third journal (Merigó et al. 2018). The graph visualizes the most cited journals among all citations generated by ISF and the networks represent the co-citations 
between journals. Figure 2 presents the results for ISF considering a minimum citation threshold of 20 citations and visualizing the one hundred strongest co-citation links. Excluding the self-citations, MIS Quarterly continues to be the journal most cited in ISF. Some other highly cited journals in ISF are Communications of the ACM, Information Systems Research, Decision Support Systems and Management Science. A more interesting coupling analysis is on the most common keywords of ISF. This is very useful in order to see the leading topics that are published in the journal. For doing so, the work uses co-occurrence of author keywords (Gaviria-Marin et al. 2018) in order to identify the most frequent keywords in ISF and connect through a network visualization those keywords that appear frequently in the same articles. Figure 3 presents the results considering a minimum threshold of 3 occurrences and the one hundred strongest connections. 


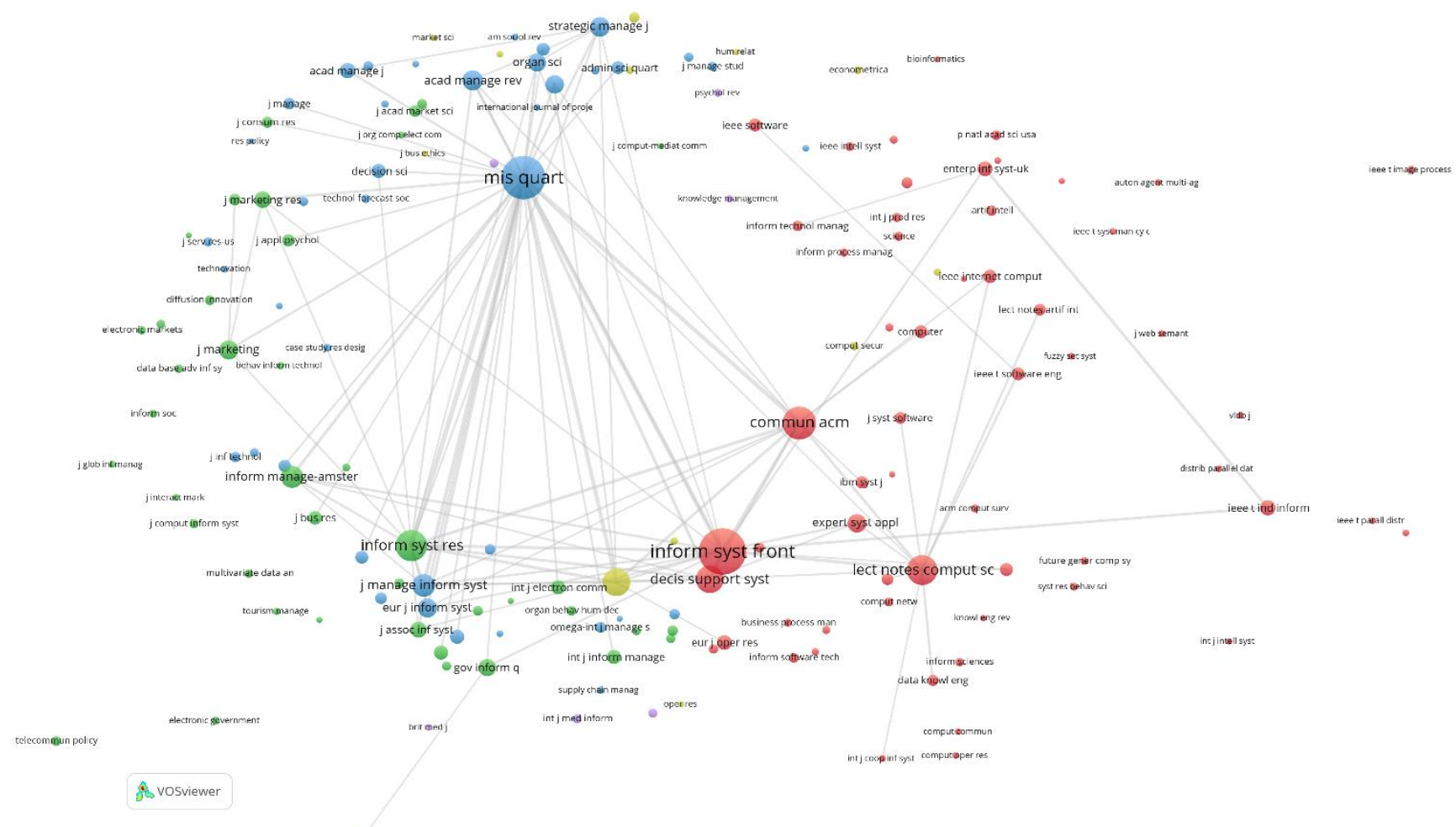

Figure 2. Co-citation of journals in ISF

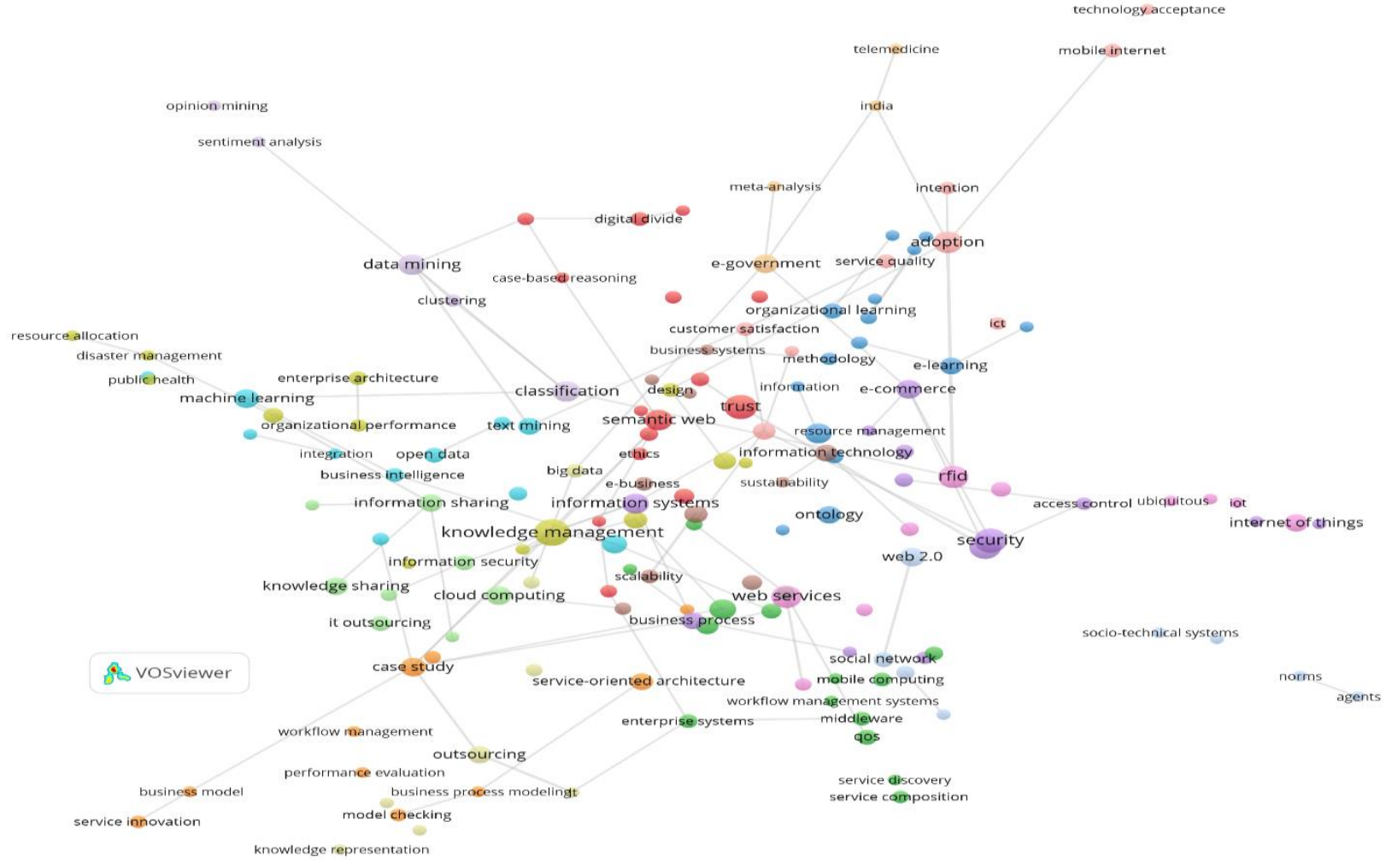

Figure 3. Co-occurrence of author keywords in ISF 
Knowledge management is the most common keyword according to the author selection made for classifying their articles. Some other popular keywords are Security, Trust, Privacy, Semantic Web, and Webs Services. Keywords in this Figure were then led to the making of the high-level themes in Table 6.

Next, let us see how the popularity of keywords has evolved over time by considering two different periods: 2003-2012 and 2013-2017. Figures 4 and 5 shows the results considering a minimum threshold of three occurrences and one hundred co-occurrence links.

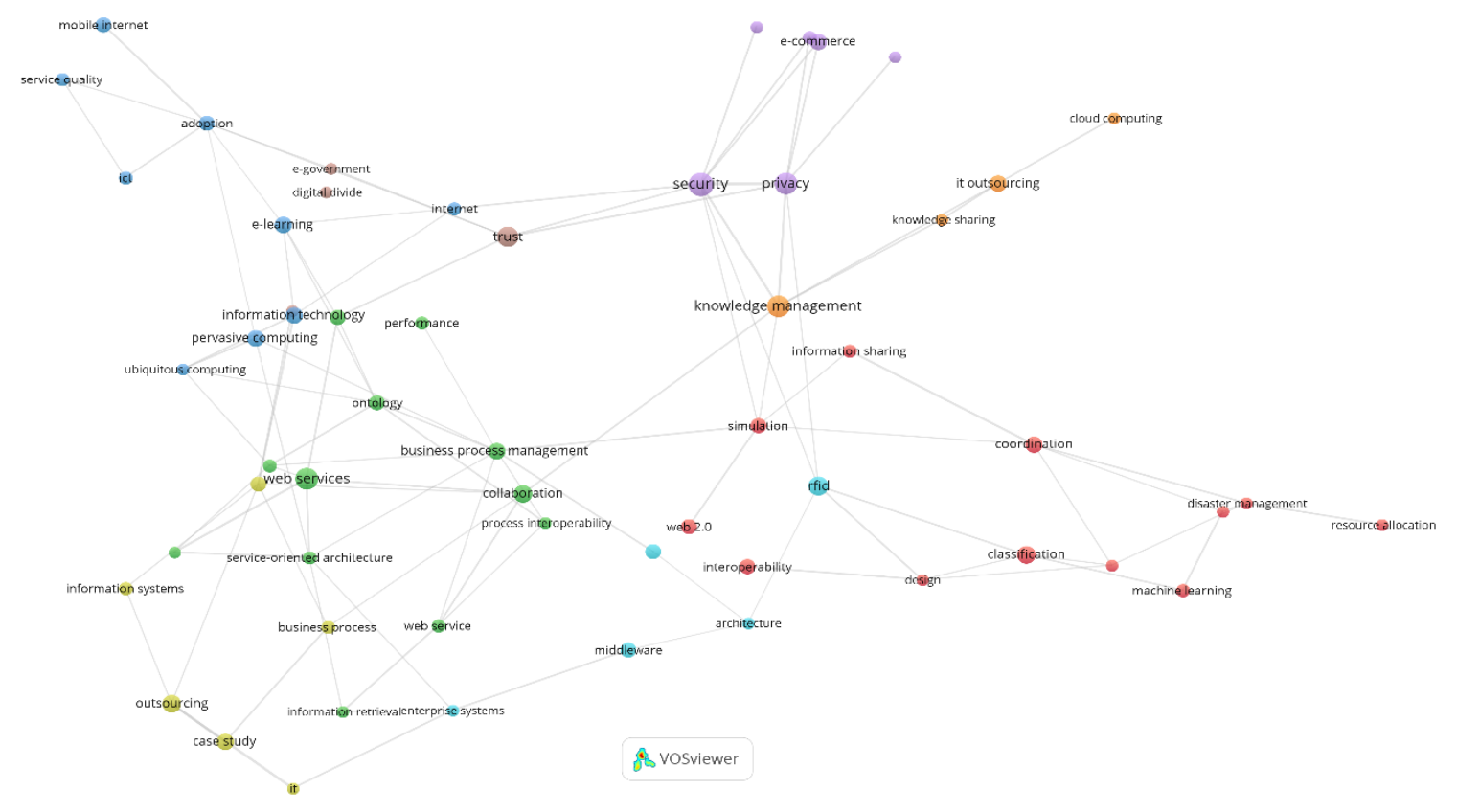

Figure 4. Co-occurrence of author keywords in ISF: 2003-2012

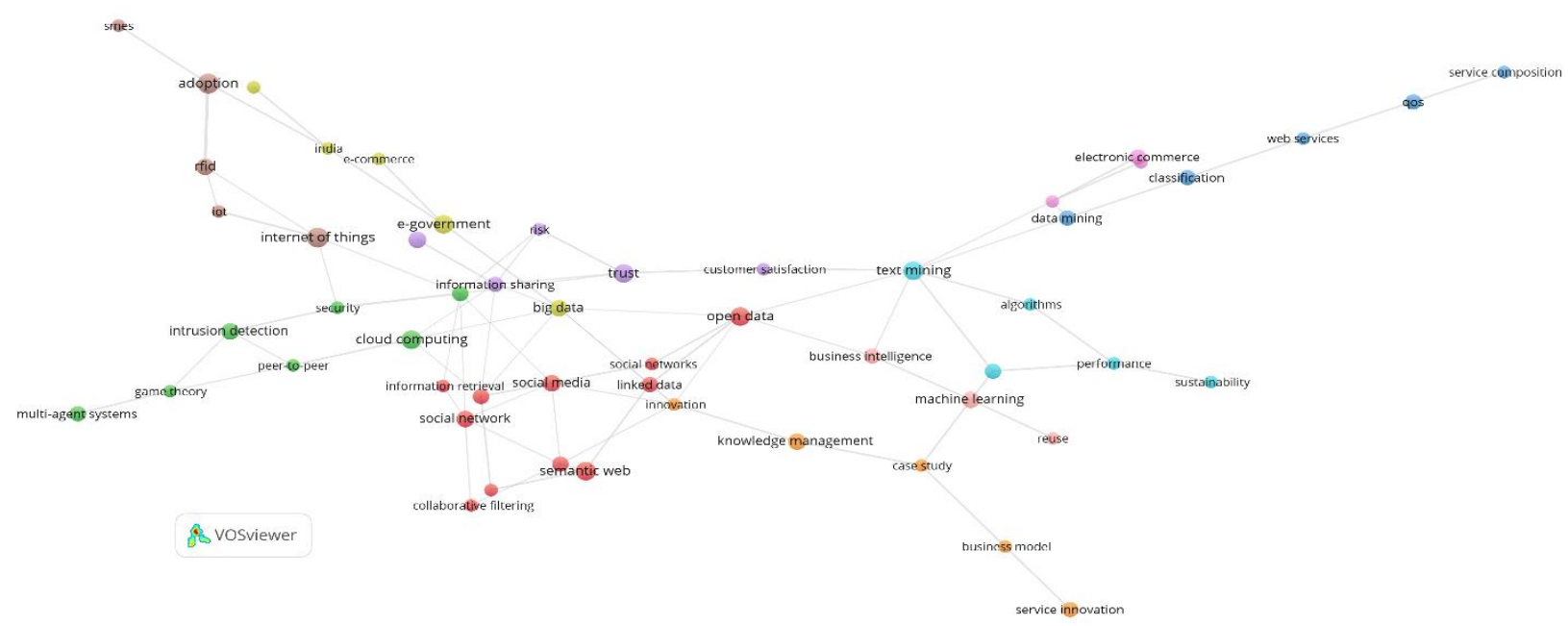

Figure 5. Co-occurrence of author keywords in ISF: 2013-2017 
The above figures show the dynamic and evolving state of the journal over the period of the study. During the last five years, many new emerging keywords, especially those related to modern technologies appeared in the journal. A comparison of the most frequent keywords reveal that the focus of IS research has shifted from Knowledge Management, Information Sharing, and Business Process Management research and in the 2003-2012 period to Open Data, Business Intelligence, Social Media, and Internet of Things in 20132017 range. Interestingly, keywords related to Security and Privacy have almost equally received authors' attention in both analyses shown in Figure 4 and 5. This reflects the importance of research on IS security, and suggests that there are still various and remaining problems in this domain worthy of further investigation.

\section{Thematic Analysis Based on Keywords}

We generalized the keyword analysis into a thematic analysis. A total of 3200 keywords as well as the number of their frequency of use were extracted and recorded in an Excel file. Keywords in our context are empirical attributes of the papers (as used by the authors in the 'keywords' list). In the earlier analysis paper (Bang 2015), keywords were synthesized using semantic analysis tools on the introductions of the papers. In our analysis, semantic analysis is applied to synthesize the themes, as described in what follows. Two IS experts, first and second author, undertook a semantic analysis on these keywords. This consisted of the following four steps:

- Given that the majority of keywords only occurred once in our list, it was important to group them for extracting high level themes. Thus, each expert independently went through the keywords. Keywords with frequencies higher than 4 were selected for identifying high level themes. The keywords used were the ones identified by the authors by the paper (and used in Scopus for indexing).

- The experts then grouped keywords into 'themes' based on their similarities. Each expert independently chose a name for each theme.

- The experts then met and discussed disagreements. A reconciliation took place, which led to 10 themes with their underlying keywords. 
- Next, these themes were used to group additional keywords occurred from 1999 to 2017 to further increase the coverage beyond the cut-off of frequency of 4 .

The list was turned into a $2 \mathrm{D}$ structure (the Table 6 below). A detailed list of top keywords within each theme is shown in Appendix I.

Table 6. Common themes in ISF: General and temporal

\begin{tabular}{lcccccc}
\hline Theme & $\mathbf{1 9 9 9}-$ & $\mathbf{2 0 0 3 -}$ & $\mathbf{2 0 0 7}-$ & $\mathbf{2 0 1 1 -}$ & $\mathbf{2 0 1 5 -}$ & Total \\
& $\mathbf{2 0 0 2}$ & $\mathbf{2 0 0 6}$ & $\mathbf{2 0 1 0}$ & $\mathbf{2 0 1 4}$ & $\mathbf{2 0 1 8}$ & \\
\hline Knowledge Management & 19 & 2 & 12 & 17 & 19 & 69 \\
IS Risk Management & 2 & 11 & 19 & 29 & 19 & 80 \\
IT Based Services & 8 & 14 & 21 & 11 & 11 & 65 \\
IS Use & 13 & 18 & 39 & 31 & 35 & 136 \\
Operations Management & 12 & 2 & 13 & 14 & 17 & 58 \\
Analytics & 7 & 8 & 16 & 15 & 47 & 93 \\
Web of Future & 1 & 3 & 8 & 30 & 34 & 76 \\
IS Research Methods \& Theories & 5 & 6 & 10 & 11 & 11 & 43 \\
IoT and Ubiquitous Computing & 7 & 9 & 21 & 13 & 24 & 74 \\
Enterprise Computing \& Architecture & 5 & 11 & 9 & 18 & 17 & 60 \\
\hline
\end{tabular}

As the above Table above shows, IS Use has ranked the highest in terms of frequency of the corresponding keywords during the past two decades. This reflects that despite recent changes in the technology space, IS scholars have been steadily concerned with core IS topics over the life of the journal. Other stable streams of research in ISF are Operations Management, Knowledge Management, and Enterprise Architectures; this represents a firm interest in researching these topics in the IS and ISF community over this period. This is also evident from Table 2, as the papers by Klaus et al. (2000) as well as Ross and Vitale (2000) on ERP and Carter and Weerakkody (2008) on IT Use are amongst top cited papers in ISF.

On the other hand, interest in IoT and Ubiquitous Computing, IS Risk Management, Analytics, and Web of Future have enjoyed the sharpest increase over the same period of time among contributors. This is evidenced by Whitemore et al. (2015) and Li et al. (2015) listed as top five cited papers in ISF in Table 2 on the subject of IoT as well as Ziegler \& Lausen (2005)'s paper on social media and trust as one of the top ten cited papers in this list. This shows that ISF is maintaining currency with emerging topics of increasing importance. The consistent increase of keywords within these themes suggest that interest in these topics will continue to the near future, and more studies can be expected within IS security, data 
analytics, IoT, and social media domains in the coming years. Furthermore, the journal is increasingly becoming interested in papers that focus on IS societal good (e.g. Abedin \& Babar, 2018), and has published a number of special issues on topics such as how IS can contribute to emergency releief and disaster management, the bad, good, and ugly side of social media, and the societal impacts of big data analytics (e.g. Beydoun et al., 2018).

Finally, the number of studies concerned with IS research methods and theories have had a gradual increase in the past twenty years. This reflects ISF community's increasing awareness and appreciation of theories and methodologies in IS research. A deeper analysis of keywords within this theme shows that case strudy, simulations, and design scienceare in particular popular methods of analysis amongst ISF authors.

\section{Conclusion}

This paper examined how the focus of ISF evolved over the past 20 years. The analysis revealed that ISF paper topics fall largely into two groups: one group represents a stable anchor of topics within the traditional IS themes. Another group reflects ISF research adapting and responding to key trends as they emerge. Within the anchor group, there are these topics: Operations Management, Knowledge Management, and Enterprise Architectures. This dual focus was also observed in an earlier study, Dwivedi et al. (2009), which examined a decade of Information Systems Frontiers research. The new themes we identified in the group of dynamic themes include IoT and Ubiquitous Computing, IS Risk Management, Analytics, and Web of Future. Interestingly, some of these themes were also subject of special issues flagged in that older survey Dwivedi et al. (2009) (e.g. Information Dynamics, Cyber Law, Knowledge Discovery in High Throughput Biological Domains, and Secure Knowledge Management).

Indeed, credit to the editorial team of ISF, this shows an underlying strategy to ensure that ISF is maintains currency and a firm IS identity. Our analysis does not determine whether this editorial outcome is through calculated design or through serendipidity. We also note that the IS identity of the journal has been further emphasized in an increase in the number of studies concerned with IS research methods and concomitant IS theories in a clear gradual trend in the past twenty years. Furthermore, the journal is increasingly becoming interested in papers that focus on IS societal good, and has published a number of special issues on 
related topics such as the role of IS in emergency relief and disaster management, the bad, good, and ugly side of social media, and the societal impacts of big data analytics. We anticipate that these topics will feature more strongly within the next decade of ISF.

\section{References}

Abedin, B., \& Babar, A. (2018). Institutional vs. non-institutional use of social media during emergency response: A case of twitter in 2014 Australian bush fire. Information Systems Frontiers, 20(4), 729-740.

Alonso, S., Cabrerizo, F.J., Herrera-Viedma, E., \& Herrera, F. (2009). H-index: A review focused on its variants, computation, and standarization for different scientific fields. Journal of Informetrics, 3(4), 273289.

Bang, C.C. (2015). Information Systems Frontiers: Keyword analysis and classification. Information Systems Frontiers, 17, 217-237.

Beydoun, G., Dascalu, S., Dominey-Howes, D., \& Sheehan, A. (2018). Disaster Management and Information Systems: Insights to Emerging Challenges. Information Systems Frontiers, 20(4), 649-652.

Blanco-Mesa, F., Merigó, J.M., \& Gil-Lafuente, A.M. (2017). Fuzzy decision making: A bibliometric-based review. Journal of Intelligent \& Fuzzy Systems, 32(3), 2033-2050.

Cancino, C., Merigó, J.M., Coronado, F., Dessouky, Y., \& Dessouky, M. (2017). Forty years of Computers \& Industrial Engineering: A bibliometric analysis. Computers \& Industrial Engineering, 113, 614-629.

Davis, F.D. (1989). Perceived usefulness, perceived ease of use, and user acceptance of information technology. MIS Quarterly, 13, 319-339.

Ding, Y., Rousseau, R., \& Wolfram, D. (2014). Measuring scholarly impact: Methods and practice, Springer, Switzerland.

Dwivedi, Y.K., Lal, B., Mustafee, N., \& Williams, M.D. (2009). Profiling a decade of Information Systems Frontiers' research. Information Systems Frontiers, 11, 87-102.

Fornell, C., \& Larcker, D.F. (1981). Evaluating structural equation models with unobservable variables and measurement error. Journal of Marketing Research, 18, 39-50.

Gaviria-Marín, M., Merigó, J.M., \& Popa, S. (2018). Twenty years of the Journal of Knowledge Management: A bibliometric analysis. Journal of Knowledge Management, 22, 1655-1687.

Hevner, A.R., March, S.T., Park, J., \& Ram, S. (2004). Design science in information systems research. MIS Quarterly, 28, 75-105.

Inan, D. I., Beydoun, G., Opper S. (2018). Agent-Based Knowledge Analysis Framework in Disaster Management, Information Systems Frontiers, 20(4).

Kessler, M.M. (1963). Bibliographic coupling between scientific papers. American Documentation, 14(1), 1025.

Klaus, H., Rosemann, M., \& Gable, G.G. (2000). What is ERP? Information Systems Frontiers, 2, 141-162.

Laengle, S., Modak, N.M., Merigó, J.M., \& de la Sotta, C. (2018b). Thirty years of the International Journal of Computer Integrated Manufacturing: A bibliometric analysis. International Journal of Computer Integrated Manufacturing, 31(12), 1247-1268.

Li, S., Xu, L.D., \& Zhao, S. (2015). The internet of things: A survey. Information Systems Frontiers, 17, 243259.

Merigó, J.M., Pedrycz, W., Weber, R., \& de la Sotta, C. (2018). Fifty years of Information Sciences: A bibliometric overview. Information Sciences, 432, 245-268. 
Othman, S. H., \& Beydoun, G. (2011). A disaster management Metamodel (DMM) evaluated in 11th international workshop on knowledge management and Acquisition for Smart Systems and Services. 2PKAW 2010. LNCS (LNAI), 6232, 111-125 Springer.

Ross, J.W., \& Vitale, M.R. (2000). The ERP revolution: Surviving vs thriving. Information Systems Frontiers, $2,233-241$.

Small, H. (1973). Co-citation in the scientific literature: A new measure of the relationship between two documents. Journal of the American Society for Information Science, 24, 265-269.

Van Eck, N.J., \& Waltman, L. (2010). Software survey: VOSviewer, a computer program for bibliometric mapping. Scientometrics, 84(2), 523-538.

Whitmore, A., Agarwal, A., \& Xu, L.D. (2015). The Internet of Things - A survey of topics and trends. Information Systems Frontiers, 17, 261-274.

Ziegler, C.N., \& Lausen, G. (2005). Propagation models for trust and distrust in social networks. Information Systems Frontiers, 7, 337-358. 
